\title{
НАУЧНО-ТЕХНИЧЕСКИЙ ПРОГРЕСС КАК ФАКТОР НЕЭФФЕКТИВНОСТИ БЮДЖЕТНЫХ РАСХОДОВ
}

\section{() 2020 Будович Юлия Ивановна}

доктор экономических наук, доцент, профессор Департамента экономической теории, Финансовый университет при Правительстве Российской Федерации, Россия, Москва

E-mail: JBudovich@fa.ru

ORCID: https://orcid.org/0000-0001-8691-947X

В статье доказывается, что бюджетные расходы на исследования и разработки являются самым неэффективным видом бюджетных расходов, что делает расчеты на увеличение доли бюджетного финансирования науки в ВВП до 1,0\% в 2035 г. призрачными, если только ситуация с эффективностью государственных расходов на науку не изменится.

Ключевые слова: эффективность НИОКР, стоимость НИОКР, полезность результатов НИОКР.

Научно-технический прогресс - результат такого вида деятельности, как исследования и разработки (ИиР), в связи с чем речь в настоящей статье фактически пойдет речь об ИиР как факторе неэффективности бюджетных расходов.

Российское государство традиционно находится под сильнейшим влиянием научного лобби, выражением интересов которого является увеличение внутренних расходов на ИиР (ВЗИР) в ВВП (\%). При этом требование увеличения данного показателя, причем резкого, характеризуется очевидной обоснованностью. В высокоразвитых капиталистических странах и бывшем успешном СССР ВЗИР в ВВП в разы больше. Если в России в 2017 г. они составили $1,11 \%$, то в Корее $-4,23$, Японии $-3,14$, Германии $-2,93$, США $-2,74$ [3, с. 36]. В СССР же ВЗИР вообще достигали 5\% ВВП [17]. Кроме того, общепризнано, что устойчивость развития страны обеспечивается только на пути ее инновационного развития, а его признаком является высокая доля ВЗИР в ВВП. Причем российское само еще в 2002 г. объявило, что целью его политики в области развития науки и технологий является переход к инновационному пути развития страны [11].

Как известно, особенностью России является стойкое нежелание бизнеса увеличивать затраты на ИиР (и инновации), во всяком случае, за счет собственных средств. Она показала свой фундаментальный характер в ходе реализации Стратегии развития науки и инноваций в Российской Федерации на период до 2015 года, принятой в 2006 г. (Стратегия 2015). До ее отмены в
2011 г. (см. ниже) российское научное лобби рассчитывало на то, что его экономические интересы будут реализовываться главным образом за счет российского бизнеса. На 2010 и 2015 г. Стратегия 2015 предусматривала целевое значение внебюджетных средств во ВЗИР, равное 60 и 70\% соответственно, при доле ВЗИР в ВПП, равной 2 и 2,5\% [20], из чего следует, что внебюджетные средства должны были составить в 2010 г. 1,2\% ВВП $(2 * 60 / 100)$, а в $2015-1,75(2,5 * 70 / 100)$. Накануне принятия Стратегии 2015, т.е. в 2005 г., внебюджетные средства во ВЗИР составляли всего 39\%. При ВЗИР, равных 1,07\% ВВП [19, с. 23, 103], в 2005 г. внебюджетные источники составляли всего $0,43 \%$ ВВП $(1,07 * 39,9 / 100)$, т.е. в Стратегию 2015 закладывался 4-кратный рост данного показателя $(1,75 / 0,43=4,07)$. При этом предполагалось даже падение бюджетного финансирования науки с $0,8 \%$ ВВП $(2 *(100-60) / 100)$ в 2010 г. до $0,75 \%$ ВВП $\left(2,5^{*}(100-70) / 100\right)$ в 2015 г.

Планы по увеличению ВЗИР в ВВП за счет средств российского бизнеса провалились. В 2010 г. внебюджетные источники составили всего 31,2\% ВЗИР при ВЗИР в ВВП, равных 1,13\% [19, c. 23, 103], из чего следует, что бюджетные источники финансирования науки в ВВП в 2010 г. составили только $0,35 \%$ ВВП $(1,13 * 31,2 / 100)$ вместо планировавшихся 1,2. Как итог, 2\% ВЗИР в ВВП, предусмотренные Стратегией 2015 на 2010 г., достигнуты не были, а данный показатель $(1,13 \%)$ фактически остался на уровне 2005 г. (1,07\%) $1,1 \%$, если округлить до 1 -го знака после запятой.

Последующие стратегии научно-технологического развития страны - документы страте- 
гического планирования, формирующиеся при активном участии научного сообщества - отражали значительно меньшие и снижающиеся «аппетиты» в отношении средств бизнеса, направляемых на финансирование ИиР, но, главное, предусматривали, очевидно, казавшееся более реальным повышение доли ВЗИР в ВВП за счет увеличения доли в ВВП бюджетных источников финансирования науки. И на самом деле, глубоким разочарованием в российском бизнесе как источнике благополучия российской науки наполнена принятая в 2011 г., т.е. за 4 года до окончания срока Стратегии 2015, Стратегия инновационного развития Российской Федерации на период до 2020 года (Стратегия 2020). В ней приводятся, в частности, данные рейтинга тысячи крупнейших компаний мира, осуществляющих ИиР, в котором Россия оказалась представленной лишь тремя компаниями - Газпромом (108-е место по объему затрат на ИиР в выручке $-0,6 \%)$, Автовазом $(758$-е $-0,8)$ и ОАО «Ситроникс» (868-е - 2,6), отмечается, что доля расходов на ИиР в бюджетах компаний-лидеров мирового автопрома более чем в 6 раз выше, чем у Автоваза, телекоммуникационных компаний-мировых лидеров - в 10 раз выше, чем у ОАО «Ситроникс» [15]. Очевидно, уже в 2011 г. слабо верили в то, что увеличить участие российского бизнеса в финансировании науки способна инициатива Президента РФ (поручение от 4 января 2010 г. № Пр-22) обязать крупнейшие российские госкомпании (47 организаций в первом списке) с 2011 г. принимать (актуализировать) и реализовывать у себя программы инновационного развития (ПИР), включая программы ИиР, финансируемые в том числе за счет собственных средств [2, с. 10, 19]. Во всяком случае, Стратегия 2020 предусматривала целевое значение внебюджетных источников во ВЗИР на 2016 г., равное 37\%, а на 2020-57, при ВЗИР в ВВП, равными 1,9 и $3 \%$ соответственно [15], из чего следует, что доля в ВВП бюджетных источников должна была составить в 2016 г. $1,2 \%(1,9 *(100-37) / 100)$, а в $2020-1,3$ (3,0*(100-57)/100). Накануне же принятия Стратегии 2020, т.е. в 2010 г., фактическое значение доли бюджетного финансирования науки в ВВП, при доле внебюджетных источников во ВЗИР 31,2\% и доле ВЗИР в ВВП 1,13\% [19, с. 23, 103], составляло $0,78 \%\left(1,13^{*}(100-31,2) / 100\right)$. Таким образом, Стратегией 2020 предусматривался рост доли бюджетных источников финансирования науки в ВВП в течение 10 лет на целых
$2 / 3(1,3 / 0,78=1,67)$.

Неслучайно в это время стала усиленно культивироваться идея о бюджетном недофинансировании науки в России, в частности активно выноситься в заголовки публикаций о состоянии отечественной науки. Эта идея отражена, например, в название статьи Е. Онищенко «Наука на бюджетных задворках. Как Россия экономит на науке» (2016). В самой работе проводится мысль, что бюджетные средства, выделяемые на науку (а также образование и здравоохранение) руководство страны рассматривает как «заначку», которую в случае чего можно истратить на другие (более важные) нужды (например, на содержание силовых ведомств и государственного управления) [10].

Но расчет научного лобби на увеличение доли ВЗИР в ВВП за счет повышения доли в ВВП бюджетных источников финансирования науки также не оправдался. По факту в 2016 г., т.е. в год принятия новой стратегии научно-технологического развития страны (см. ниже), внебюджетные источники финансирования во ВЗИР составили 34,1\% при В3ИР в ВПП, равных 1,1\% [19, с. 23, 103], из чего следует, что доля бюджетных источников финансирования науки в ВВП составила в 2016 г. 0,72\% (1,1*(100-34,1)/100)), вместо 1,2 на этот год, заложенных в отмененной Стратегии 2020 (см. выше). В 2017 же году внебюджетные источники финансирования во ВЗИР составили $36,2 \%$ при ВЗИР в ВПП, равных 1,11\% [19, с. 23, 103], из чего следует, что доля бюджетных источников финансирования науки в ВВП составила в 2017 г. 0,71\% $\left(1,11^{*}(100-36,2) / 100\right)$, т.е. стала еще ниже.

Возникает вопрос, почему российское руководство, несмотря на сильнейшее давление со стороны научного лобби, да и вопреки собственным обещаниям (все-таки стратегии научно-технологического развития утверждаются документами, подписываемыми первыми лицами государства), вот уже много лет упорно держит долю в ВВП бюджетных средств, направляемых на финансирование науки, на определенных и низких, исходя из общего уровня финансирования науки в стране, значениях, а в последние годы даже снижает ее?

Для ответа на данный вопрос нужно доказать, что бюджетные расходы на ИиР являются самым неэффективным видом бюджетных расходов в России. Очевидно, что российское государство, определяя меру своего участия в тех или иных 
расходах в экономике, так или иначе сравнивает эффективность бюджетных расходов на различные нужды. Осознание крайней неэффективности бюджетных расходов на ИиР и не позволяет ему идти на сколь-нибудь заметное увеличение доли бюджетных средств, направляемых на науку. Под эффективностью бюджетных расходов на оплату работ, в том числе ИиР, в настоящей статье понимается отношение полезности результатов работы к ее стоимости. Отсюда, требуется доказать, что стоимость ИиР, оплачиваемых государством, завышается по сравнению со стоимостью других работ (а также продукции и услуг), а полезность результатов ИиР, наоборот, ниже полезности последних.

О завышении цены на ИиР в госконтрактах по сравнению с ценами на другие товары, приобретаемые за счет бюджетных средств, можно легко судить по данным о величине откатов в стоимости контрактов на госзакупки. Откат вознаграждение лицу (лицам), как правило чиновнику, от которого зависит доступ к госзаказу, за обеспечение такого доступа, уплачиваемое в виде определенного процента от величины госконтракта.

Самой откатоемкой отраслью российской экономики всегда было строительство. В № 16/2011 Бюллетеня Оперативной Информации «Московские Торги» содержится информация о том, как в госконтрактах на ремонт завышается его цена (в скобках указан\% увеличения): 1) включение в смету работ, которые не будут выполнены или будут выполнены только частично, и это невозможно проверить (10-15), 2) завышение стоимости материалов, которое также нельзя проверить (5-7), 3) завышение оплаты труда в связи с тем, что реально используется труд гастарбайтеров $(10), 4)$ включение стоимости испорченных материалов и затрат на вывоз мусора (1,5-2) [12]. Таким образом, максимальное завышение равно $34 \%(15+7+10+2)$ от нормальной цены. Реальные же откаты ниже. Согласно тому же Бюллетеню, откат за заключение договора по ремонту составляет 10-30\% [12]. В 2009 г. в Воронеже деньги на строительство дорог распределялись по компаниям за откат в 10-30\% стоимости подряда, а по данным Forbes, сметчиков и строителей средний откат чиновникам за дорожный контракт в том году составлял 15\% стоимости договора [14]. Субподрядчик «Петроинвест» при строительстве СИЗО «Кресты» передал в 2010-2015 гг. замначальнику управления ФСИН по Санкт-Петербургу и Ленобласти откатов в размере $12 \%$ от суммы полученных средств [8]. Таким образом, приведенные данные говорят, что откаты в строительстве находятся в основном в диапазоне 10-30\%.

Конечно же, есть исключительные случаи. По данным на 2017 г. одной санкт-петербургской строительной фирмы, откаты за строительство составляют 5-10\%, хотя при осуществлении строительно-монтажных работ доходят до 40\% [1]. Тот же Бюллетень Оперативной Информации № 16/2011 сообщает, что при строительстве дорог откат может достигать 50\% от суммы договора [12].

Но с некоторых пор в самую откатоемкую отрасль российской экономики превратились Ии Р. На IX Международном Форуме «Инновационное развитие через рынок интеллектуальной собственности»» (г. Москва, 7 апреля 2017 г.) было отмечено, что за последние 20 лет сфера ИиР стала одной из наиболее коррупциогенных областей и реальной угрозой национальной безопасности. И если в 2007-2009 гг. откаты составляли треть бюджетных расходов на ИиР, то сейчас доходят до половины [16]. Заметим, что речь идет не об отдельных откатах, о доле откатов во всей величине бюджетных расходов на Ии Р.

Есть виды ИиР-лидеры по откатам. Это ИиР, связанные с информационно-коммуникационными технологиями. По данным президента Национальной ассоциации инноваций и развития О. Усковой, в 1996-1999 гг. откаты здесь составляли 10-15\%, в 1999-2003 - 20, после появления Федерального агентства по информационным технологиям, в 2003-2005 - 35, в 2005-2008 - 40, в 2008-2009 - 60, а в 2010 г. размер отката достиг 70-75\% [6]!

Это также оборонные Ии Р. По данным на 2011 г. размер отката здесь составлял 70\%, а его максимальная величина достигала 80\% от стоимости госконтракта [4]. Следует отметить, что бюджетные расходы на военные НИОКР в 2017 г. составили 364 млрд. руб. [22, с. 9]. От общей величиной ВЗИР в стране в том году, равной 1019 млрд. руб. [3 с. 34], это 36\% (364/1019*100).

Сравним завышение цены за счет откатов в строительстве и Ии Р.

Вначале рассмотрим масштабы хищения бюджетных средств при разных уровнях откатов. Разы завышения цены определяются по формуле $\mathrm{X}=100 /(100-Y)$, где X - разы завышения, Y процент отката. Пусть нормальная цена госкон- 
тракта равна 100 руб. Тогда, чтобы заплатить 10\% от его стоимости, и при этом остались необходимые для выполнения ИиР 100 руб., нужно завысить цену в 1,11 раза $(100 /(100-10))$. При откате в 20\% цена заказа завышается в 1,25 раза (100/ (100-20)), 30-1,43 (100/(100-30)), 40-1,67 (100/ $(100-40))$, а в $50 \%$ - уже в 2 раза $(100 /(100-50))$ ! Дальше - больше. При откате в 60\% цена завышается в 2,5 раза $(100 /(100-60)), 70-$ в 3,33 (100/ (100-70)), $75-4(100 /(100-75))$, а в $80 \%$ - в 5 раз (100/(100-80))! Видно, что всего 5-процентная разница межу 75- и 80-процентным откатом означает, что чиновник украл еще одну нормальную стоимость госзаказа. Напомним, что откат 80\%, соответствующий 5-кратному завышению стоимости ИиР, выше рассматривался как максимальный в оборонных НИОКР. Но, как выясняется, по крайней мере в 2012 г. было нормой завышение НИИ Минобороны себестоимости ИиР в 5-10 раз [9].

Прирост процента хищений от нормальной цены госзаказа при одинаковом приросте процента отката подчиняется закону растущей доходности (закон растущей доходности отката). Первые $10 \%$ отката привели к завышению нормальной цены госконтракта на 11\% $((1,11-1,0) * 100)$, его рост с 10 до $20 \%$ - еще на $14 \%\left((1,25-1,11)^{*} 100\right)$, с 20 до $30-$ на $18((1,43-$ $\left.1,25)^{*} 100\right)$, с 30 до $40-$ на $24\left((1,67-1,43)^{*} 100\right)$, с 40 до 50 - на 33 ((2,0-1,67)*100), с 50 до 60 - на 50 $((2,5-2,0) * 100)$, с 60 до $70-$ на $83\left((3,33-2,5)^{*} 100\right)$, с 70 до $80 \%$ - еще на $167 \%((5,0-3,33) * 100)$.

При верхней границе обычных откатов в строительстве, равной 30\%, нормальная цена завышается в 1,43 раза, а в ИиР, равной $50 \%-$ в 2 раза, т.е. стоимость ИиР по сравнению со стоимостью строительства завышается в 1,4 раза $(2 / 1,43)$. При рекордном откате в строительстве, равном $50 \%$, цена завышается в 2 раза, а в ИиР, равном 80\% - в 5 раз, т.е. ИиР по равнению со строительством в этом случае обходятся госбюджету в 2,5 раза дороже $(5 / 2)$.

Но, как выясняется главной составляющей относительной неэффективности бюджетных расходов на ИиР является вовсе не завышенная стоимость, а пониженная полезность результатов бюджетных Ии Р.

Традиционно лидером антирейтинга по качеству исполненного госзаказа, в данном случае отражающему уровень полезности его результатов, считается то же дорожное строительство лидер в отрасли по величине отката. Но уровень полезности дорог, построенных по госзаказу, не идет ни в какое сравнение с таковым результатов ИиР, осуществленных по госконтрактам. Дорожные строители в подавляющем большинстве случаев в обмен на полученные от государства деньги предоставляют ему предметы, обладающие полезностью, т.е. дороги, по которым можно ездить, хотя, может быть, и без должного уровня комфорта или только первое время. Случаи сдачи государству дорожными строителями за полученные от него сполна деньги бесполезных продуктов крайне редки и целиком относятся к разряду криминала. Исполнители же ИиР за предусмотренные госконтрактами деньги сплошь и рядом предоставляют государству абсолютно бесполезные результаты, хотя, может быть, в большинстве случаев, и без злого умысла (из-за принципиальной недостижимости результатов, оговоренных в госконтракте, или из-за их превращения в бесперспективные), в связи с чем в этом не обнаруживается никакого криминала.

В оценке полезности результатов ИиР можно полагаться на мнение самих исследователей или близких к ним людей. После отставки министра образования и науки Д.Ливанова в Информационном агентстве «Национальная служба новостей» была проведена пресс-конференция на тему «Куда уходят образовательные миллиарды? Коррупционные итоги года» (11 декабря 2014 г.), на которой директор Республиканского НИИ интеллектуальной собственности В. Лопатин сообщил, что 9 из 10 НИОКР по заказу Минобрнауки ничем не закачиваются [24]. Об уровне полезности результатов ИиР, заказываемых государством, можно судить и по данным официальных проверок. В 2009 г. в рамках 1586 госконтрактов на ИиР было потрачено 6,2 млрд. руб. Полезный результат - два образца программного обеспечения стоимостью 30 млн. руб., даже не запатентованных [13]. Уже из приведенного выше названия пресс-конференции ясно, что главной причиной низкой полезности ИиР у нас являются не особенности научного производства, а его имитация. Проверки тех же 1586 контрактов вскрыли чудовищные масштабы плагиата в отчетах по НИОКР - до 58\% текста составляли цитаты, зачастую даже без ссылок на источники, и выдержки из российского законодательства. В этом плане всех превзошел отчет за 50 млн. руб., выделенные на НИОКР из госбюджета Росатому, состоявший из кандидатских диссертаций 
и дипломных работ, добытых в Интернете [13]. Об имитации говорит и закрытие ИиР патентами на бесполезные или устаревшие изобретения. Так, результаты проверок Генпрокуратуры НИОКР двойного назначения и анализ работы Роспатента показали, что в 2011-2014 гг. было заключено более 200 госконтрактов на соответствующие НИОКР на сумму около 95 млрд. руб., по которым было зарегистрировано 450 патентов, никак не воплотившихся в жизнь [18].

И завышенная стоимость бюджетных ИиР по сравнению с другими товарами, приобретаемыми государством, и, главное, крайне заниженная полезность их результатов, указывают на то, что бюджетные расходы на ИиР в России характеризуются крайней неэффективностью, и, следовательно, некогда сделанный газетой «Ведомости» резкий вывод, что эффективность государственных расходов на НИОКР в нашей стране практически равна нулю [22], имеет весомое право на истину.

Ситуацию с низкой эффективностью бюджетных расходов на ИиР не исправило и их перераспределение в пользу крупнейших госкомпаний, начавших с 2011 г. реализовывать ПИР (см. выше) - средства госбюджета во ВЗИР госкомпаний увеличились со 117 млрд. руб. в 2010 г. до 249 в 2013 [2, с. 19]. Очевидно, российское руководство рассчитывало на их заинтересованность в результативности ИиР (в связи со спросом, обеспечиваемым программами инноваций, софинансированием ИиР). Интересно, что накануне эксперты оценивали ситуацию с полезностью результатов ИиР в госкомпаниях как более удручающую, чем в госсекторе науки. В частности, отмечалось, что менеджеры госкомпаний оставшиеся после отката деньги уже просто «приватизируют», не утруждая себя даже имитацией ИиР, что в 2010 г. выход международных патентов на 1 рубль затрат на ИиР в госкомпаниях был в 5 раз меньше, чем в среднем по «казенному» сектору, в связи с чем эксперт назвал госкомпании «черной дырой» бюджетных расходов на НИОКР [13].

В этих условиях трудно было ожидать како- го-то существенного эффекта от прироста затрат на ИиР госкомпаний. Как деликатно отмечается в докладе, посвященном первым итогам реализации госкомпаниями ПИР, увеличение затрат на ИиР в 2010-2013 гг. не всегда означает пропорциональную динамику генерации новых знаний и технологий [2, с. 22]. В докладе об инновациях в России в 2016 г. было отмечено, что резкий рост расходов на НИОКР в ПАО «НК «Роснефть»» не отразился на количестве патентов, а расходы на НИОКР в ПАО «ТАТНЕФТЬ» приносят большое количество патентов, качество патентов у всех российских компаний крайне низкое - они не востребованы для дальнейших разработок ни в России, ни за рубежом, фактически на выходе представлены либо уже устаревшие, либо просто неактуальные технологии [7, с. 40]. Замминистра экономического развития РФ О. Фомичев в 2017 г. признал, что с привлечением госкомпаний для обеспечения инновационного роста экономики государство зашло в тупик, что инновационные блоки в них не прижились [5].

Очевидно, низкая эффективность бюджетных расходов на ИиР не может не выступать фактором, удерживающим российское руководство от увеличения доли ИиР в расходах бюджета или расходов бюджета на науку в ВВП.

В настоящее время более скромный, но все же ориентир роста бюджетных расходов на науку в ВВП, задает Стратегия научно-технологического развития Российской Федерации (до 2035 г.), утвержденная в 2016 г., согласно которой в 2035 г. ВЗИР в ВВП должны составить не менее 2,0\%, а доля внебюджетных источников их финансирования - не менее $50 \%$ [21], т.е. бюджетные расходы на ИиР должны составить 1,0\% ВВП. Если ситуация с эффективностью государственных расходов на ИиР не изменится, будет оставаться сомнение в том, что данные расходы поднимутся выше нынешних 0,7\% ВВП, которые государство, очевидно, скорее рассматривает не как источник развития науки, а как социальную гарантию для персонала, занятого ИиР.

\section{Библиографический список}

1. Баранюк Ю. «По умолчанию $10 \%$, но в строительстве я сталкивался с 40\%». Подрядчик рассказывает про откаты в России.- URL: https://www.currenttime.tv/a/28724627.html.

2. Гершман М.А., Зинина Т.С., Романов М.А. и др. Программы инновационного развития компаний с государственным участием: Промежуточные итоги и приоритеты.- М.: НИУ ВШЭ, 2015.-128 с. 
3. Городникова Н.В., Гохберг Л.М., Дитковский К.А. и др. Наука. Технологии. Инновации: 2019: краткий статистический сборник.- М.: НИУ ВШЭ, 2019.- 84 с.

4. Ищенко С. Армейский вестник. Недовооружённые силы России.- URL: https://army-news.ru/2011/03/ nedovooruzhyonnye-sily-rossii/.

5. Как пробудить спящих гигантов? // Сайт Минэкономразвития РФ. 13.01.2017. - URL: http://old.economy.gov. $\mathrm{ru} / \mathrm{minec} / \mathrm{about} / \mathrm{structure/depIno/2017130114.}$

6. Корчагин Ю. Мнение ученого. Коррупция, имитация и профанация.- URL: http://communa.ru/ekonomika/ mnenie_uchenogo-_korruptsiya-_imitatsiya_i_profanatsiya/.

7. Кузнецов Е.Б. и др. Национальный доклад об инновациях в России 2016. - М.: НИУ ВШЭ, 2016. - 104 с.

8. Маракулин Д. За «Кресты» платили откаты и убивали. Закончено дело о коррупции при строительстве крупнейшего СИЗО Европы // Коммерсантъ. № 233. 18.12.2018. - URL: https://www.kommersant.ru/doc/3834290.

9. Ненасытные НИОКР. - URL: http://forum.spnet.ru/threads/63682/.

10. Онищенко E. Наука на бюджетных задворках. Как Россия экономит на науке.- URL: https://www.gazeta.ru/ science/2016/01/20_a_8032067.shtml.

11. Основы политики Российской Федерации в области развития науки и технологий на период до 2010 года и дальнейшую перспективу (утв. Президентом РФ 30 марта 2002 г. № Пр-576.- URL: https://base.garant. $\mathrm{ru} / 12127915 /$.

12. «Откат» за «откатом» - как на морском берегу [Электронный ресурс]. - Режим доступа: http://www.e-torgi. ru/index.php/stati-2/1149-otkat-za-otkatom-kak-na-morskom-beregu.

13. Пожидаев Е. «Инноваторы» и распил. - URL: http://www.rosbalt.ru/business/2011/07/22/871814.html.

14. Попов И. Дорожный разбор. - URL: https://www.forbes.ru/ekonomika/lyudi/27446-dorozhnyi-razbor.

15. Правительство Российской Федерации. Распоряжение от 8 декабря 2011 года № 2227-р [Об утверждении Стратегии инновационного развития Российской Федерации на период до 2020 года] (с изменениями на 18 октября 2018 года). - URL: http://docs.cntd.ru/document/902317973.

16. Рекомендации участников IX Международного Форума «Инновационное развитие через рынок интеллектуальной собственности». г. Москва, 7 апреля 2017 г. Итоговый документ. - URL: http://structure.sfu-kras.ru/ files/structure/rniiis_itogi.pdf.

17. Рогов С.М. РФ: наука и НИОКР. Выдержка из доклада.-URL: https://ss69100.livejournal.com/1875749.html.

18. СМИ: Генпрокуратура нашла нарушения в госконтрактах на НИОКР.- URL: https://news.rambler.ru/ incidents/29748684-genprokuratura-nashla-narusheniya-v-goskontraktah-na-niokr/.

19. Статистика науки и образования. Выпуск 6. Затраты и источники финансирования научных исследований и разработок. Инф.-стат. мат.-М.: ФГБНУ НИИ РИНКЦЭ, 2018. - 200 с.

20. Стратегия развития науки и инноваций в Российской Федерации на период до 2015 года. - URL: http://docs. cntd.ru/document/902367266.

21. Указ Президента РФ от 1 декабря 2016 г. № 642 «О Стратегии научно-технологического развития Российской Федерации».- URL: https://www.garant.ru/products/ipo/prime/doc/71451998/.

22. Широв А.А., Гусев М.А., Фолов И.Э. Макроэкономические эффекты оборонных расходов России: ретроспективный анализ и прогноз // Проблемы прогнозирования. - 2018. - № 4 (169). - С. 3-16.

23. Чечель А., Товкайло М. Эффективность госрасходов на НИОКР практически равна нулю. - URL: https://www. vedomosti.ru/politics/articles/2011/01/17/effektivnost_gosrashodov_na_niokr_prakticheski_ravna_nulyu.

24. Эксперты: Коррупцию в Минобре одной отставкой Ливанова не победить.- URL: http://nsn.fm/hots/ gosduma-korruptsiyu-v-obrazovanii-otstavkoy-livanova-ne-iskorenit.php (дата обращения: 24.10.2018). 